\title{
Bronchoscopic Lung Volume Reduction For Pulmonary Emphysema: Preliminary Experience With Endobronchial Occluder
}

\author{
Liqiang Song PhD, Feng Zhao PhD, Xinyu Ti PhD, Weiqiang Chen PhD, \\ Gaowen Wang, Changgui Wu PhD, and Yan Li PhD
}

\begin{abstract}
OBJECTIVE: To describe the self-expanding endobronchial occluder, as utilized in bronchoscopic lung volume reduction, with a 36 month follow-up procedure. METHODS: Twenty-three subjects with severe emphysema were recruited and underwent flexible bronchoscopic placement of selfexpanding endobronchial occluders. Outcomes were assessed at 1 week, 1-month, 3-, 6-, 12-, 24-, and 36-month intervals. Feasibility, safety, and efficacy were analyzed by means of pulmonary function testing, 6-min walk test, dyspnea score, BODE (body mass index, air-flow obstruction, dyspnea, and exercise capacity) index, and St George's Respiratory Questionnaire. RESULTS: Fifty-eight self-expanding endobronchial occluders were implanted into 23 lobes previously selected. No displacement was found during the follow-up. Five subjects experienced postoperative complications of cough, and 6 subjects had lobar pneumonia, which were not located in any of the blocked segments. The $\mathrm{FEV}_{1}$ in 18 subjects was improved by $>15 \%$, compared with baselines $(P<.001)$, and the mean first efficacy time and maximal efficacy time were $5.65 \pm 1.51$ months and $6.35 \pm 3.08$ months, respectively. No significant changes were observed in FVC or the ratio of residual volume to TLC. The 6-min walk distance, dyspnea score, and St George's Respiratory Questionnaire total score were improved in 22 subjects over a 24-month period, and a minority of subjects continued to improve through to the end of the study. Mean baseline BODE index had improved during follow-up, but not at the study's conclusion. CONCLUSIONS: This preliminary study demonstrates early significant improvements in pulmonary function, 6-min walk distance, dyspnea score, BODE index, and quality of life after placement of the self-expanding endobronchial occluder in bronchoscopic lung volume reduction. Its placement also proved both easy and safe. However, the initial improvements were maintained long-term for only a minority of subjects. Key words: emphysema; bronchoscopic lung volume reduction; endobronchial occluder; pulmonary function; safety. [Respir Care 2013;58(8):1351-1359. ( 2013 Daedalus Enterprises]
\end{abstract}

\section{Introduction}

COPD is a major cause of chronic morbidity and mortality throughout the world, characterized by air-flow limitation that is not fully reversible. ${ }^{1}$ In China the overall prevalence of COPD is $8.2 \%$ (men $12.4 \%$, women $5.1 \%$ ) with stage $3(1.7 \%)$ and stage $4(0.4 \%)$ in individuals

The authors are affiliated with the Department of Respiratory Medicine, with the exception of $\mathrm{Dr} \mathrm{Li}$, who is affiliated with the Department of Cardiology, Xi Jing Hospital, Fourth Military Medical University, Xi'an, China.

The authors have disclosed a relationship with Huayishengjie Medical, Beijing, China, which partly funded this research, and which manufactures the self-expanding endobronchial occluder. $\geq 40$ years old, and there are about 1 million deaths and over 5 million disabilities each year caused mainly by COPD. ${ }^{2}$ So how to improve the symptoms and life quality of patients with severe COPD is an urgent social problem.

None of the existing medications for COPD has been shown to modify the long-term decline in lung function that is the hallmark of this disease. ${ }^{3,4}$ Bronchoscopic lung volume reduction (BLVR), as an alternative to lung vol-

\footnotetext{
Correspondence: Yan Li PhD, Department of Cardiology, Xijing Hospital, Fourth Military Medical University, 17 Changle West Road, Xi'an, China 710032. E-mail: liyanshaanxi@gmail.com.
}

DOI: $10.4187 /$ respcare. 02218 
ume reduction surgery (LVRS), has shown promise and has reached later-stage clinical trials. ${ }^{5,6}$ Most BLVR methods attempt to induce atelectasis by the implantation of endobronchial devices, including bronchial occluders, bronchial valves, glues, and bio-modulators. In all clinic trials to date, most patients have had selectively placed different types of one-way (expiratory) valves in the target airways. ${ }^{7-9}$ These valves were designed to block air from entering the target area during inspiration, while allowing gas to exit during exhalation. This was intended to cause collapse and volume reduction by promoting progressive deflation in damaged regions of the lung, and reducing the potential for post-obstructive pneumonia.

However, no particular valve has proven to be consistently effective in generating atelectasis and volume reduction or producing durable clinical benefit in patients. No clinical trial could demonstrate that valves were more effective and had fewer complications than occluders. Sabanathan and colleagues reported that $5 / 8$ subjects with endobronchial occluders had improvements in well-being, dyspnea, exercise tolerance, lifestyle, and medication requirements. ${ }^{10}$ But there was lack of long-term follow-up. Most clinical trials showed improvement of pulmonary function and exercise tolerance in some subjects in whom atelectasis did not occur. ${ }^{11,12}$

The self-expanding endobronchial occluder (SEEO) was designed by author Liqiang Song and made by Huayishengjie Medical, in Beijing. The SEEO is a novel implantable device designed as a nitinol shape memory wire mesh packed with layers of polyester non-woven fabrics, and is placed by flexible bronchoscopy with local anesthesia. In unpublished dog model studies the placement of SEEO could induce the target lobar area into collapse or atelectasis. This report describes the preliminary human study results with the SEEO to determine feasibility, safety, and efficacy data before proceeding to a larger pivotal clinical trial.

\section{Methods}

\section{Subjects}

We conducted a preliminary, prospective, nonrandomized, single-center longitudinal cohort study. Twenty-three subjects with severe heterogeneous emphysema were recruited according to visiting sequence and inclusion and exclusion criteria used by Wan et $\mathrm{al}^{13}$ (Table 1 ). They underwent BLVR between August and December 2006, and received follow-up visits for 36 months. All subjects had severe dyspnea, with Borg scores $\geq 5.0$ on exertion, despite medical treatment before procedure, and accepted examinations, including baseline physiologic, radiologic, and quality-of-life testing. The distribution of emphysema was heterogeneous, as seen by computed tomography (CT)

\section{QUICK LOOK}

\section{Current knowledge}

Lung-volume-reduction surgery for emphysema improves lung function and quality of life, but the postoperative complications can be severe and expensive, so non-surgical methods such as bronchial occlusion are being studied.

\section{What this paper contributes to our knowledge}

In patients with COPD, self-expanding endobronchial occluders significantly improved 6-min walk distance, dyspnea, BODE (body mass index, air-flow obstruction, dyspnea, exercise capacity) index, and quality of life, but the improvements persisted long-term in a minority of patients.

and ventilation-perfusion scintigraphy. Each subject had full pulmonary function tests, arterial blood gas measurements, transthoracic echocardiography, 6-min walk test, dyspnea score, and BODE (body mass index, air-flow obstruction, dyspnea, and exercise capacity) index. Quality of life was assessed with the St George's Respiratory Questionnaire (SGRQ). All the tests were on the same day for each subject, and met American Thoracic Society criteria. The study was approved by the Xijing Hospital ethics committee, and all subjects provided informed written consent for the procedures, data collection, and participation in the clinical trial.

\section{Materials}

The SEEO is an implantable device designed for placement in the segmental or subsegmental bronchi by means of flexible bronchoscopy. Each occluder is made of a nitinol wire mesh that is shaped into a stacked-discuses shape with 3 collars to secure the occluder in the target airway, with several layers of polyester fabric inserts designed to block air flow (Fig. 1). As the occlusion device is implanted, it expends outward and the collars push against the wall of the airway.

\section{Procedure}

The procedure was performed in the bronchoscopy laboratory. Subjects were placed supine with the head slightly extended, and underwent local anesthesia and sedation. The target areas for SEEO placement were previously selected on the basis of pulmonary CT scan, and the most affected segments were blocked with valves of appropriate size. A flexible bronchovideoscope (BF-240, Olympus, 
Table 1. Inclusion and Exclusion Criteria

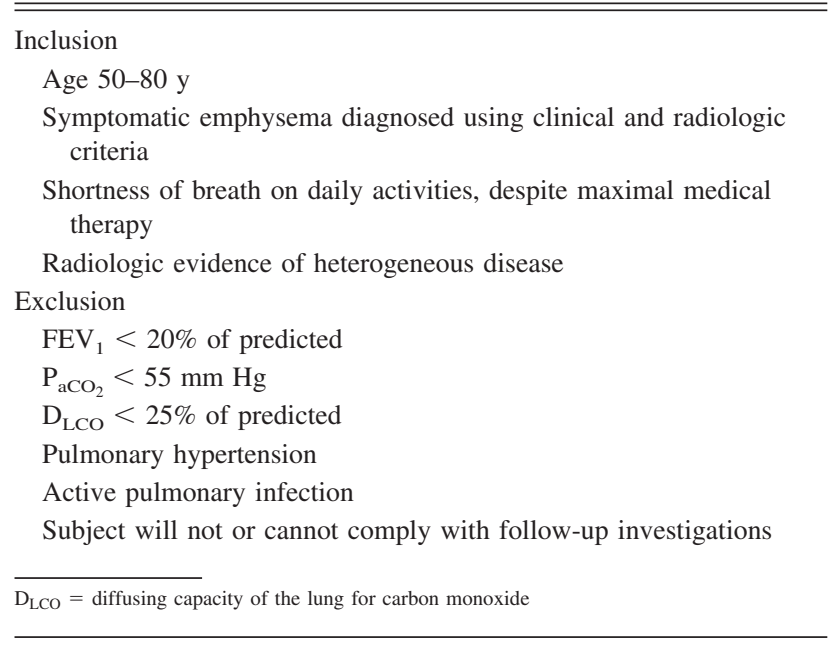

Tokyo, Japan) passed through the mouth to reach the target bronchial orifices. A guide wire $(0.9 \mathrm{~mm}$ external diameter) was threaded through the instrument channel of the bronchoscope into the target bronchus. The bronchoscope was pulled out, but another bronchoscope (BF-P240, Olympus, Tokyo, Japan) passed through the nares to the central airway in order to monitor the procedure. The delivery catheter was advanced over the guide wire to the bronchial orifice, and then the guide wire was removed. Under direct observation with the video bronchoscope, the selected SEEO of appropriate size (4 diameter sizes of $5.0 \mathrm{~mm}, 6.0 \mathrm{~mm}, 7.0 \mathrm{~mm}$, and $8.0 \mathrm{~mm}$ are available) was advanced to the distal end of the delivery catheter and deployed or retrieved using the delivery cable with screw attachment for the occluders. When the SEEO was conformed to block the target bronchus, it would be released by unscrewing the delivery cable from the device. The delivery catheter and cable were removed, followed by a final visual inspection.

\section{Postoperative Care and Follow-Up}

After the procedure, each subject had a chest radiograph taken immediately, and was required to be hospitalized for minimum of 2 days. Subjects received prophylactic antibiotics such as amoxicillin ( $0.25 \mathrm{~g}, 3$ times/d), clavulanate (0.25 g, 3 times/d), levofloxacin ( $0.4 \mathrm{~g}$, once a day), as well as inhaled salbutamol postoperatively. All COPD management routines were continued. Subjects returned for follow-up evaluation by the investigators at 1 week, and 1-, 3-, 6-, 12-, 24- and 36-month intervals. The primary end point was safety, as measured by the incidence of migration, erosion, and/or infection related to the occlusion device. Other safety measures included the presence of persistent cough, bronchitis, pneumonia, respiratory failure, hemoptysis requiring intervention, death, and unpredictable adverse events. Participants in the study were invited to contact the investigators at any time after the procedure. Chest CT scan or bronchoscopy were requested at each visit to document the stability of the position of the occlusion device. During follow-up, each subject received an examination consisting of a full pulmonary function test, arterial blood gas measurements, 6-min walk test, dyspnea score assessment, BODE index, SGRQ (for 3 months). Furthermore, all subjects were encouraged to receive appropriate pulmonary rehabilitation.

Four variables were identified prospectively as pilot study measures for efficacy after the procedure: an increase in $\mathrm{FEV}_{1}$ of $\geq 15 \%$, an increase in 6-min walk distance of $\geq 15 \%$, a decrease in dyspnea score of $\geq 1$, or an improvement in SGRQ total score of $>4$ units. These thresholds for minimal clinically important differences were based on published literature. ${ }^{13}$

\section{Statistical Analysis}

All descriptive statistics are expressed as mean \pm SD for continuous variables, and as median (range) for ordinal

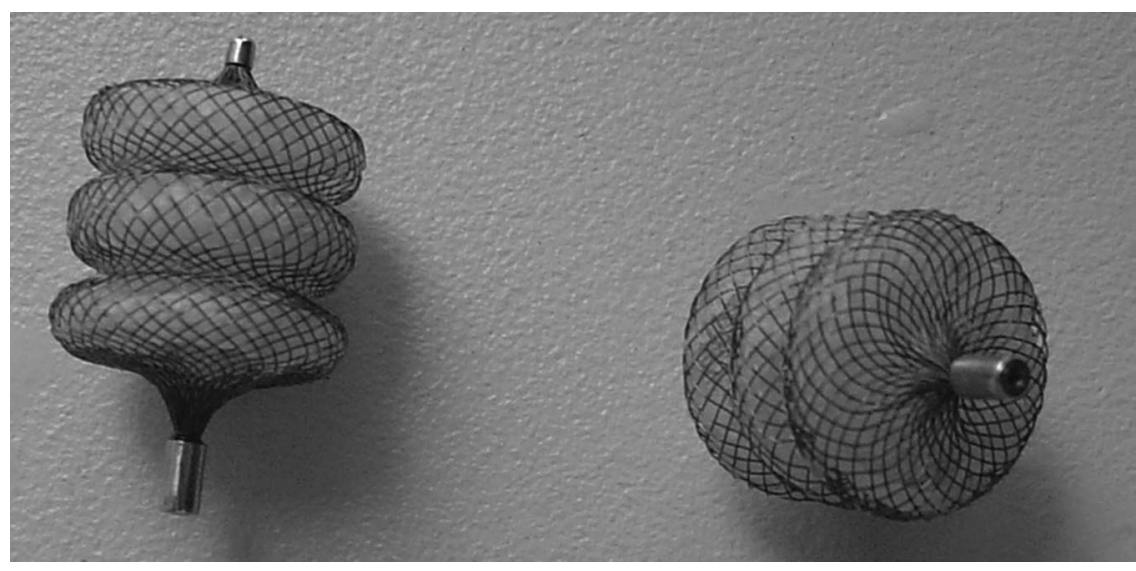

Fig. 1. The self-expanding endobronchial occluder. 
Table 2. Baseline Data of Subjects*

\begin{tabular}{|c|c|c|c|}
\hline & $($ mean $\pm \mathrm{SD})$ & (range) & $\begin{array}{l}\text { Percent of Predicted } \\
\quad(\text { mean } \pm \text { SD })\end{array}$ \\
\hline Age, y & $66.57 \pm 5.38$ & $58-75$ & \\
\hline $\mathrm{pH}$ & $7.39 \pm 0.05$ & $7.31-7.43$ & \\
\hline $\mathrm{P}_{\mathrm{aO}_{2}}, \mathrm{~mm} \mathrm{Hg}$ & $64.14 \pm 10.90$ & $56.00-87.2$ & \\
\hline $\mathrm{P}_{\mathrm{aCO}}, \mathrm{mm} \mathrm{Hg}$ & $38.50 \pm 6.62$ & $28.00-47.33$ & \\
\hline $\mathrm{FEV}_{1}, \mathrm{~L}$ & $0.98 \pm 0.31$ & $0.56-1.32$ & $35.23 \pm 11.23$ \\
\hline FVC, L & $2.33 \pm 0.56$ & $1.63-2.87$ & $66.78 \pm 15.50$ \\
\hline $\mathrm{FEV}_{1} / \mathrm{FVC}, \%$ & $43.15 \pm 12.27$ & $28.04-60.68$ & $54.00 \pm 15.34$ \\
\hline $\mathrm{RV}, \mathrm{L}$ & $4.13 \pm 1.30$ & $2.39-6.24$ & $176.04 \pm 44.72$ \\
\hline TLC, L & $6.36 \pm 0.90$ & $4.75-7.20$ & $112.02 \pm 13.64$ \\
\hline RV/TLC, \% & $60.00 \pm 9.42$ & $50.31-75.00$ & $155.0 \pm 23.56$ \\
\hline $\begin{array}{l}\mathrm{D}_{\mathrm{LCO}}, \mathrm{mmol} / \\
\mathrm{min} / \mathrm{mm} \mathrm{Hg}\end{array}$ & $18.59 \pm 6.56$ & $10.45-25.86$ & $61.35 \pm 18.37$ \\
\hline $6 \mathrm{MWD}, \mathrm{m}$ & $388 \pm 105.05$ & $186-602$ & \\
\hline Dyspnea score & $3.32 \pm 0.67$ & 2-4 & \\
\hline BODE index & $5.48 \pm 1.62$ & $2-8$ & \\
\hline SGRQ total score & $63.59 \pm 7.00$ & $50-83$ & \\
\hline $\begin{array}{l}* 20 \text { male, } 3 \text { female } \\
\text { RV }=\text { residual volume } \\
\text { TLC = total lung capac } \\
\text { D }_{\text {LCO }}=\text { diffusing capac } \\
\text { 6MWD = 6-min walk } \\
\text { BODE }=\text { body mass in } \\
\text { SGRQ }=\text { St George's }\end{array}$ & $\begin{array}{l}\text { ity } \\
\text { ity of the lung for carbo } \\
\text { listance } \\
\text { dex, air-flow obstruction } \\
\text { lespiratory Questionnaire }\end{array}$ & $\begin{array}{l}\text { on monoxide } \\
\text { dyspnea, and exe }\end{array}$ & ercise capacity \\
\hline
\end{tabular}

data. Paired 2-tailed $t$ tests were used to analyze quantitative continuous variables, comparing the means for the groups. The Friedman test and the Wilcoxon ranksum test were used for ordinal variables. Bonferroni correction was used to adjust the observed significance level when multiple comparisons of the means were made. Analyses were done with statistics software (SAS 9.1.3, SAS Institute, Cary, North Carolina). $P$ values were calculated with variance analysis, with $P<.05$ judged significant.

\section{Results}

\section{Clinical Characteristics}

In the preliminary study a total of 23 subjects underwent the procedure described previously from August to December 2006 (Table 2). All SEEOs were implanted unilaterally in the segmental or subsegmental airways previously selected. Only one lobe was involved in each subject, and the target airways were located in the center of predominantly heterogeneous emphysema rather than indiscriminately in all segments of one lobe. The number of SEEOs inserted for each subject was relative to the individual morbid anatomy. Overall, 58 SEEOs were implanted into 23 lobes (mean 2.52 occluders per subject), in which there were 8 lower lobes (34.8\%) and 15 upper lobes $(65.2 \%)$. Only 2 entire lobes were blocked, while in the remaining 21 incomplete lobar occlusions were performed (Table 3). There were no procedure-related airway tissue lacerations or deaths associated with the procedure. Most of subjects were discharged at the third day postprocedure. Only 2 subjects stayed in hospital for 7 days, because of moderate cough and expectoration, but experienced no fever or pneumonia.

During the 36 months allowed for follow-up, all subjects finished their return visits according to their individual schedules. Both chest imaging and bronchoscopy views demonstrated fully functioning devices, with no evidence of displacement (Fig. 2). Five subjects experienced complications consistent with mild or moderate (grade 1 or 2 measured by the cough score scale) cough, but without purulent sputum and fever during the immediate postoperative period. These symptoms were gradually ameliorated with the administration of inhaled bronchodilator and anti-tussive agents. Six subjects suffered from lower lobe pneumonia during the follow-up. Three occurred about 12 months after the procedure, and were located in the remaining left lower lobe with the occlusive atelectasis of lateral and posterior basal segments. Pseudomonas aeruginosa was isolated in the sputum culture. After antibiotic treatment and local bronchoalveolar lavage under bronchoscopy, the focus of infection was gradually absorbed and left some fibrous scarring. In another case, pneumonia of the infected lobe was different from the target lobe, and also responded to treatment. Other usually reported complications, such as pneumothorax, hemoptysis, and thorax pain, were never observed. Only 2 subjects experienced atelectasis of target lobes, as observed by chest CT scan at 3 months and 12 months postprocedure, respectively (Figs. 3 and 4).

\section{Spirometric and Functional Assessments}

For lung function, the $\mathrm{FEV}_{1}$ in 18 subjects $(78.26 \%)$ was improved $>15 \%$, compared with baselines. The beginning efficacy time and maximal efficacy time were $5.65 \pm 1.51$ months and $6.35 \pm 3.08$ months, respectively. Compared with the maximal $\mathrm{FEV}_{1}(1.17 \pm 0.25 \mathrm{~L})$, the baseline $\mathrm{FEV}_{1}(0.94 \pm 0.22 \mathrm{~L})$ was improved 24.47\% (0.23 L) $(P=.004)$ (Table 4) (Fig. 5). In addition, comparing with the baseline, 8 subjects maintained $>10 \%$ improvement of $\mathrm{FEV}_{1}$ at the end time point $(P=.04)$. Note that the treatment of COPD from the Toward a Revolution in COPD Health (TORCH) investigators maintained only a $0.029 \%$ increase in $\mathrm{FEV}_{1}$, indicating the positive effect of this endobronchial occluder. ${ }^{14}$ 
Table 3. Clinical Characteristics and Complications of Subjects

\begin{tabular}{|c|c|c|c|c|}
\hline $\begin{array}{l}\text { Subject } \\
\text { Number }\end{array}$ & $\begin{array}{c}\text { Number } \\
\text { of } \\
\text { Valves }\end{array}$ & Lobe Valved & Post-Procedure Complications & Outcome \\
\hline 1 & 2 & Left lower & $\begin{array}{l}\text { Cough and expectoration immediately, } \\
\text { pneumonia at } 12 \text { months }\end{array}$ & Ameliorated, cured \\
\hline 2 & 2 & Right upper & None & \\
\hline 3 & 3 & Left upper & None & \\
\hline 4 & 2 & Left upper & None & \\
\hline 5 & 3 & Right lower & Pneumonia at 8 months & Cured \\
\hline 6 & 2 & Left lower & None & \\
\hline 7 & 3 & Right upper & Cough immediately & Ameliorated \\
\hline 8 & 3 & Right lower & Pneumonia at 8 months & Cured \\
\hline 9 & 2 & Left upper & None & \\
\hline 10 & 2 & Left lower & Pneumonia at 12 months & Cured \\
\hline 11 & 3 & Left upper & None & \\
\hline 12 & 2 & Right upper & None & \\
\hline 13 & 3 & Right lower & None & \\
\hline 14 & 2 & Left lower & $\begin{array}{l}\text { Cough and expectoration immediately, } \\
\text { pneumonia at } 8 \text { months }\end{array}$ & Cured \\
\hline 15 & 2 & Right upper & None & \\
\hline 16 & 3 & Right upper & Cough immediately & Ameliorated \\
\hline 17 & 2 & Left upper & None & \\
\hline 18 & 3 & Left upper & None & \\
\hline 19 & 3 & Right upper & None & \\
\hline 20 & 2 & Left lower & Pneumonia at 12 months & Cured \\
\hline 21 & 3 & Left upper & None & \\
\hline 22 & 3 & Right upper & Cough immediately & Ameliorated \\
\hline 23 & 2 & Right upper & None & \\
\hline
\end{tabular}

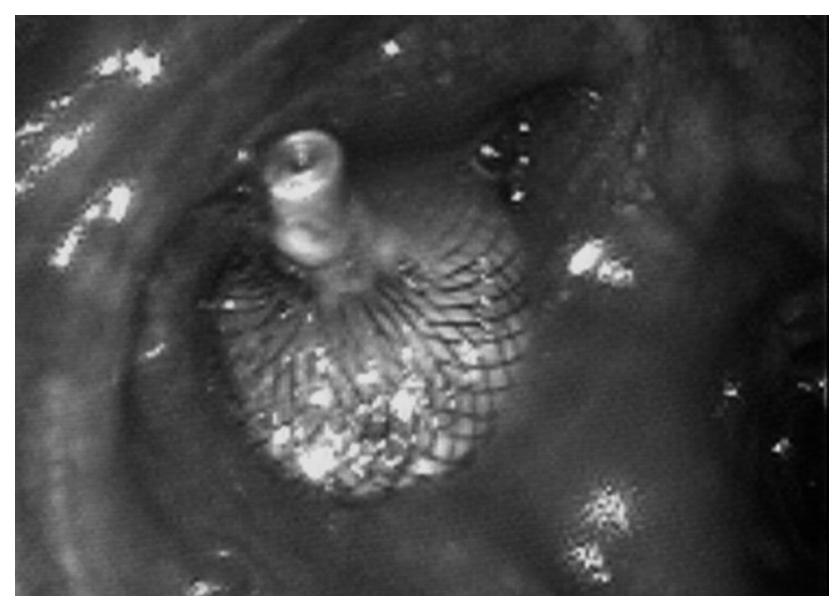

Fig. 2. Bronchoscopic view of a self-expanding endobronchial occluder in bronchus orifice, 1 month post-insertion.

Six-min walk distance showed an improvement of $>15 \%$, compared with baseline, in 22 subjects $(95.65 \%)(P<.001)$. The beginning efficacy time and maximal efficacy time were $3.19 \pm 2.69$ months and $13.09 \pm 5.81$ months, respectively. At the end time only 12 subjects $(52.17 \%)$ kept the improvement. Like- wise, dyspnea score in 22 subjects $(95.65 \%)$ decreased $>1$ point $(P<.001)$, and the 2 time-points were $5.36 \pm 5.16$ months and $7.27 \pm 5.06$ months, respectively. The dyspnea scores of 7 subjects (30.43\%) showed a 1-point decrease at the end of the study $(P=.02)$ (see Table 4).

Compared with mean baseline BODE index (6.09 \pm 1.59), the values at 3,6 , and 12 months post-BLVR were variously improved: $5.13 \pm 1.49(P=.03), 4.74 \pm 1.57$ $(P=.03)$, and $5.00 \pm 1.62(P=.02)$. But BODE index did not continue to show sustained improvements in the remaining time (Fig. 6).

\section{Health-Related Quality of Life Assessments}

At 3 months post-BLVR, the SGRQ scores were evaluated. In 20 subjects $(86.96 \%)$ the total scores were improved $>4$ units, compared with baseline, and the beginning efficacy time and maximal efficacy time were $3.27 \pm 0.88$ months and $12.56 \pm 5.11$ months, respectively. At the end of the study follow-up, 16 subjects $(69.57 \%)$ revealed a $>4$-unit improvement (see Table 4) $(P=.02)$. 

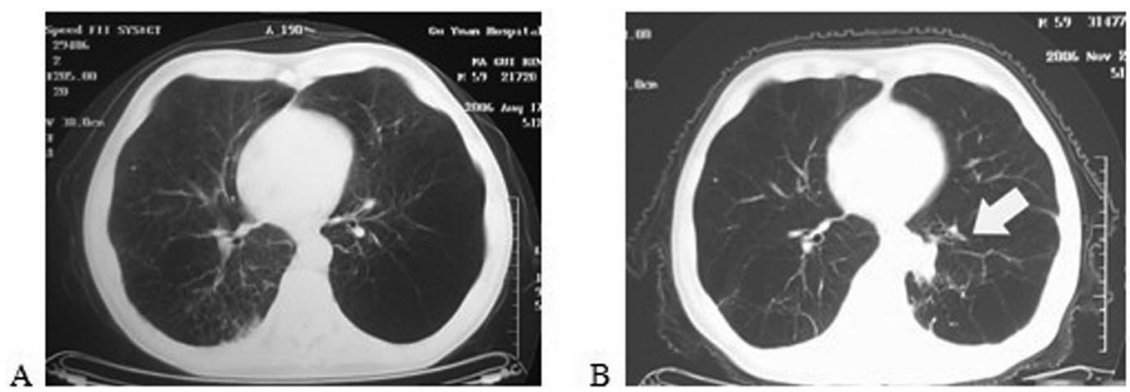

Fig. 3. Computed tomography sections before (left) and 3 months after (right) insertion of self-expanding endobronchial occluders in a 58-year-old male subject with left-lower-lobe-predominant, severe panlobar emphysema. Two self-expanding endobronchial occluders were placed, in the lateral and posterior basal segment bronchi in the left lower lobe, and occlusive atelectasis was visible at 3 months (arrow).

A1

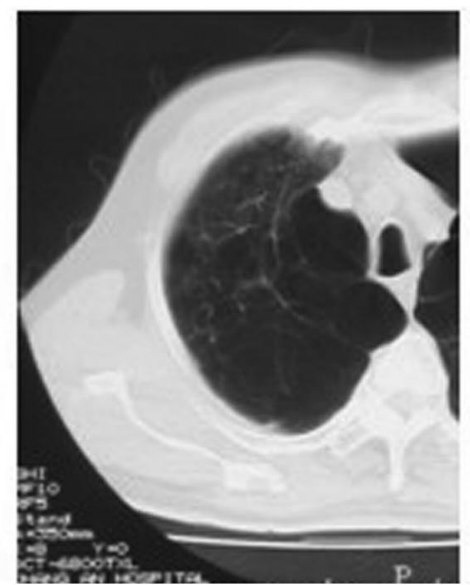

B1
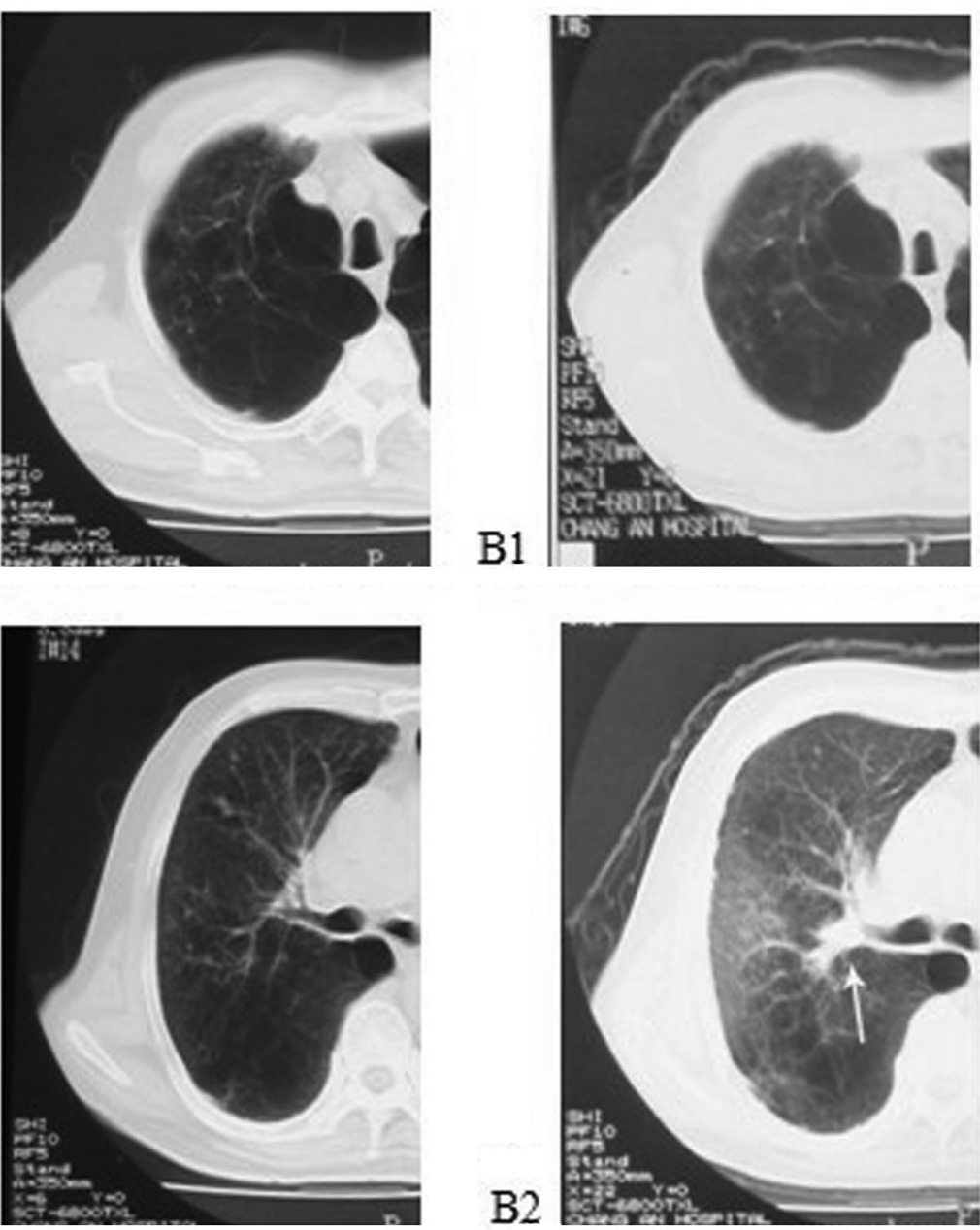

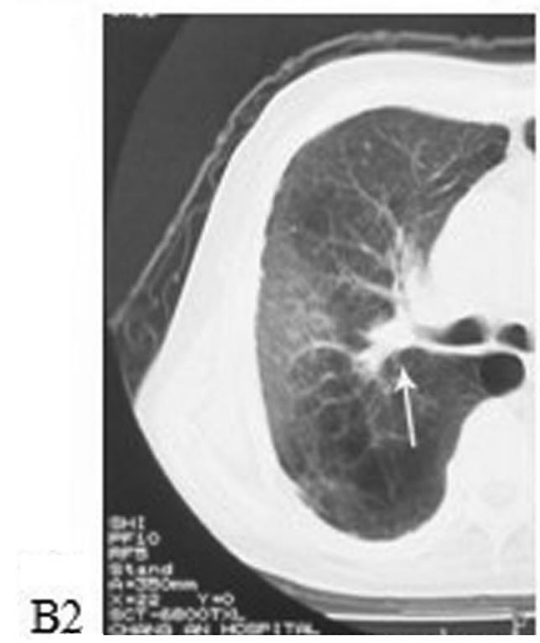

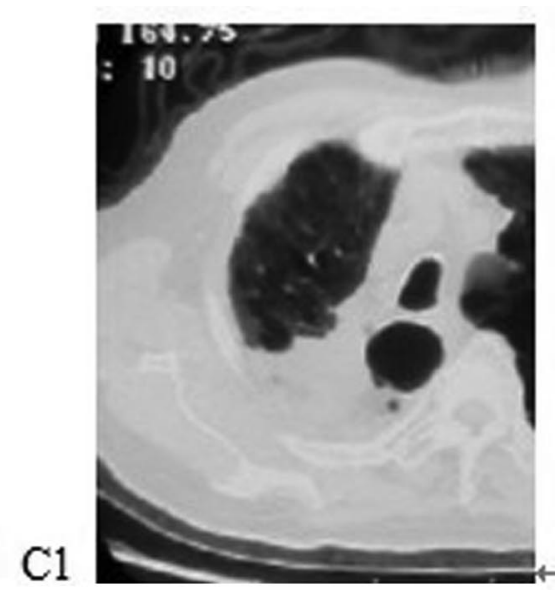

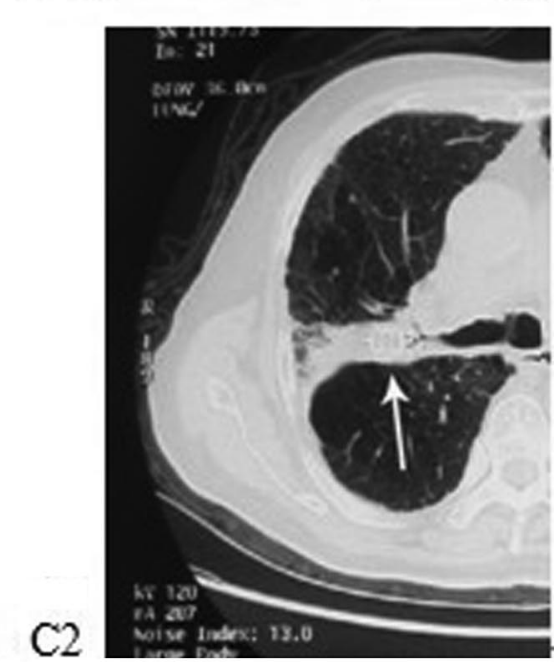

Fig. 4. Computed tomography sections before (A1, A2), 6 months (B1, B2) after, and 12 months (C1, C2) after insertion of selfexpanding endobronchial occluders in a 69-year-old male subject with right-upper-lobe-predominant, severe panlobular emphysema. Two self-expanding endobronchial occluders were placed, in an apical segment bronchus (B1, C1) and a posterior segment bronchus (B2, C2) (arrow) in the right upper lobe. Occlusive collapse and atelectasis were visible at 3 months and 12 months.

\section{Discussion}

BLVR is characterized by blocking the target airway, and how to design the blocker is still an unresolved problem. SEEO was designed differently from previous airway occluders, including stent and balloon. ${ }^{10}$ The results demonstrated that early improvements were statisti- 
Table 4. $\mathrm{FEV}_{1}, 6 \mathrm{MWD}$, Dyspnea Score, and Health-Related Quality of Life Score

\begin{tabular}{|c|c|c|c|}
\hline & $\begin{array}{l}\text { At Beginning } \\
\text { of Improvement }\end{array}$ & $\begin{array}{l}\text { At Maximal } \\
\text { Improvement }\end{array}$ & $\begin{array}{l}\text { At End of } \\
\text { Follow-up }\end{array}$ \\
\hline \multicolumn{4}{|l|}{$\mathrm{FEV}_{1}$} \\
\hline Improvement $\geq 15 \%$, no. $(\%)$ & $18(78.26)$ & $18(78.26)$ & \multirow[t]{2}{*}{$5(21.74)$} \\
\hline Time, mean \pm SD (range) min & $5.65 \pm 1.51(1-12)$ & $6.35 \pm 3.08(1-12)$ & \\
\hline Change from baseline, mean $\pm \mathrm{SD}$ & $0.25 \pm 0.03^{*}$ & $0.23 \pm 0.03 *$ & $0.01 \pm 0.03$ \\
\hline \multicolumn{4}{|l|}{$6 \mathrm{MWD}$} \\
\hline Improvement $\geq 15 \%$, no. $(\%)$ & $22(95.65)$ & $22(95.65)$ & \multirow[t]{2}{*}{$12(52.17)$} \\
\hline Time, mean $\pm \mathrm{SD}$ (range) min & $3.19 \pm 2.69(0.25-12)$ & $13.09 \pm 5.81(1-12)$ & \\
\hline Change from baseline, mean $\pm \mathrm{SD}$ & $67.36 \pm 8.58 \dagger$ & $104.43 \pm 11.86^{*}$ & $62.78 \pm 6.94 \dagger$ \\
\hline \multicolumn{4}{|l|}{ Dyspnea score } \\
\hline Improvement $\geq 1$ grade, no. (\%) & $22(95.65)$ & $22(95.65)$ & \multirow[t]{2}{*}{$7(30.43)$} \\
\hline Time, mean $\pm \mathrm{SD}$ (range) min & $5.36 \pm 5.16(1-24)$ & $7.27 \pm 5.06(1-24)$ & \\
\hline Change from baseline, mean $\pm \mathrm{SD}$ & $-1.06 \pm 0.02 \dagger$ & $-1.38 \pm 0.01 \dagger$ & $-0.18 \pm 0.12$ \\
\hline \multicolumn{4}{|l|}{ SGRQ total score } \\
\hline Improvement $\geq 4$ units, no. (\%) & $20(86.96)$ & $20(86.96)$ & \multirow[t]{2}{*}{$16(69.57)$} \\
\hline Time, mean $\pm \mathrm{SD}$ (range) min & $3.27 \pm 0.88(3-6)$ & $12.56 \pm 5.11(3-24)$ & \\
\hline Change from baseline, mean $\pm \mathrm{SD}$ & $-8.79 \pm 0.11 \dagger$ & $-12.69 \pm 1.89 *$ & $-5.17 \pm 1.06 \dagger$ \\
\hline 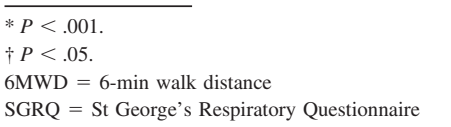 & & & \\
\hline
\end{tabular}

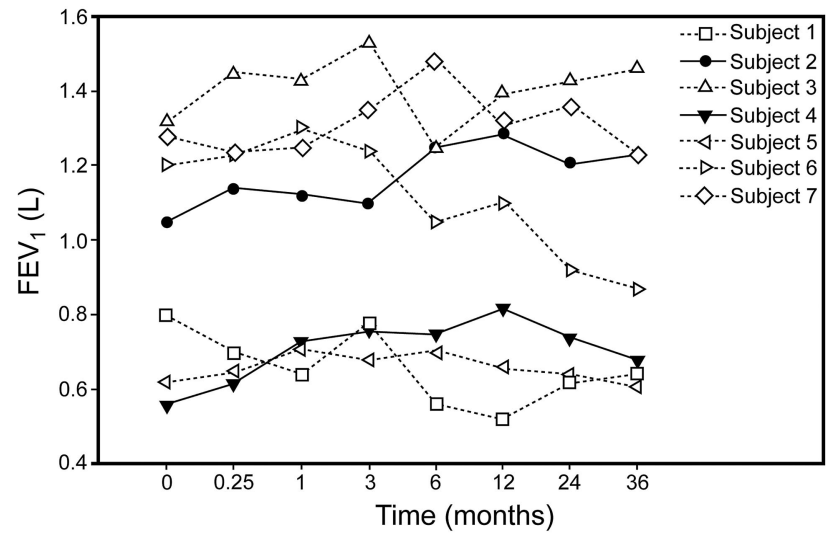

Fig. 5. Change in $\mathrm{FEV}_{1}$ in subjects 1-7.

cally significant in pulmonary function, 6-min walk distance, dyspnea scores BODE index, and quality of life. Ease of placement and acceptable safety records were all positive.

Placement of SEEO was successful in all desired segments and subsegments with flexible bronchoscope and local anesthesia. With the delivery cable, the device was able to be easily adjusted, removed, or replaced. No displacement was seen under bronchoscopy or by $\mathrm{CT}$ scan. Recently, a case showed 2 endobronchial valves migrated from left upper lobe to the lower lobes of left and right, respectively. ${ }^{15}$ No severe complications were seen during the 2 days hospital stay post-procedure, so it suggests that

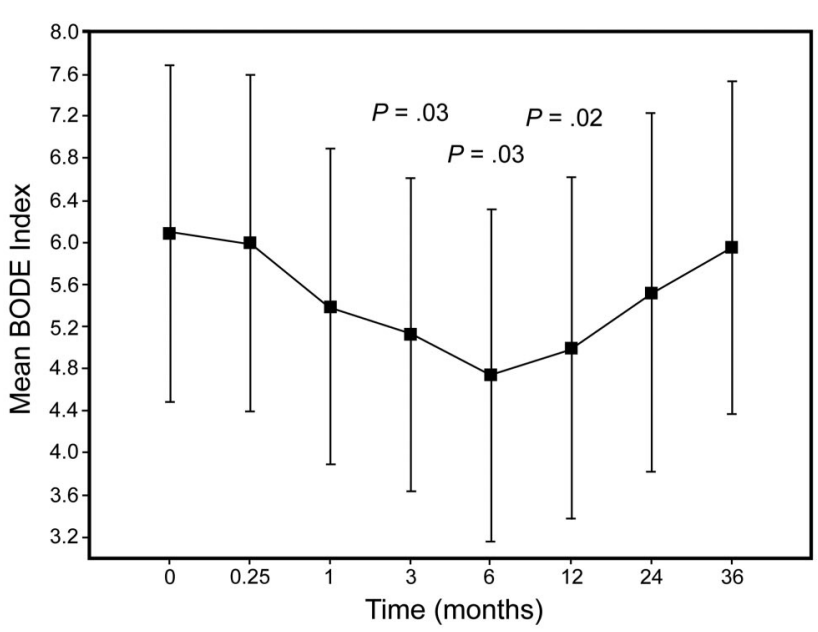

Fig. 6. Change from baseline in mean BODE (body mass index, air-flow obstruction, dyspnea, and exercise capacity) index in all subjects. The whisker bars indicate the full range of values.

insertion of SEEOs could be performed as an out-patient procedure.

In this study, 5 subjects experienced complications of cough during the immediate postoperative period, without purulent sputum and fever. The symptoms were gradually ameliorated with inhaled bronchodilator. No various relations were found between the bronchospasm incidence and the insertion location, because almost all lobes were involved in previous reports. 
Our biggest concern with complications was postobstructive pneumonia, so we undertook several preventive measures, including selecting stable stage COPD patients, culturing the target area lavage fluid, and providing prophylactic antibiotics. Unfortunately, 6 subjects suffered from lower lobe pneumonia; fortunately, it was not the direct result of the occluder insertion, although one subject had pneumonia located in the left lower lobe adjacent to the post-obstructive atelectasis. The time of occurrence was nearly 1 year after the procedure. Two causes were presumed for the lower lobe pneumonia. First, due to anatomical characteristics, the drainage of secretions in the lower lobe was apt to be inadequate. Second, the inflammation reaction and granulation tissue formation in the target airway might cause stenosis of vicinity orifices. ${ }^{16}$ Therefore, we considered that upper lobes would be selected rather than lower lobes, in order to reduce the incidence of post-obstructive pneumonia in BLVR. And LVRS outcomes are usually better in subjects with upperlobe predominant emphysema than in those with diffuse emphysema. ${ }^{17}$ Sciurba reported that the rate of pneumonia in the target lobe in the endobronchial valves group was $4.2 \%$ at 12 months. ${ }^{18}$ Kotecha reported 5/16 subjects had new microbial organisms isolated after endobronchial valve insertion. ${ }^{16}$

Most of our subjects experienced early improvements in pulmonary function, exercise tolerance, dyspnea score, BODE index, and SQRQ score. But the improvement of pulmonary function was sustained long-term in a minority of subjects. The result was in accordance with the reports from most BLVR studies. ${ }^{7,18}$ Although the therapeutic benefits of BLVR also diminish over time due to disease progression and possibly treatment-related acceleration of lung function loss, objective benefit has been observed for years after treatment. This is particularly true for subjects with upper-lobe-predominant emphysema. ${ }^{12,19,20}$ By contrast, physiological benefits after LVRS often diminish substantially within months. In general, BLVR responses still appear to be more durable than LVRS. ${ }^{20}$

\section{Conclusions}

In conclusion, this is the first detailed report on the long-term outcome of SEEO placement for emphysema treatment. The results demonstrate early significant improvements in pulmonary function, BODE index, and SGRQ score, and acceptable safety, ease of use, and procedural complication rates. But the improvement was maintained long-term in only a minority of subjects. Selecting upper-lobe-predominant emphysema as a target area, selecting a suitable size of SEEO, and inserting the SEEO step by step until atelectasis occurs will improve the safety and efficacy of BLVR. The weakness of the study is the small number of recruited subjects, a single center, and the lack of a control group. The small sample size limits our ability to draw definitive conclusions. Clarification of the occluder role in the management of severe COPD will depend on the results of larger randomized controlled trials.

\section{REFERENCES}

1. Downs CA. Functional assessment of chronic obstructive pulmonary disease. J Am Acad Nurse Pract 2011;23(4):161-167.

2. Zhong N, Wang C, Yao W, Chen P, Kang J, Huang S, et al. Prevalence of chronic obstructive pulmonary disease in China. A large, population-based survey. Am J Respir Crit Care Med 2007;176(8): 753-760.

3. Venuta F. Bronchoscopic procedures for emphysema treatment. Eur J Cardiothorac Surg 2006;29(3):281-287.

4. Pauwels RA, Buist AS, Calverley PMA, Jenkins CR, Hurd SS. Global strategy for the diagnosis, management, and prevention of chronic obstructive pulmonary disease. Am J Respir Crit Care Med 2001; 163(5):1256-1276.

5. Ciccone AM, Meyers BF, Guthrie TJ, Davis GE, Yusen RD, Lefrak $\mathrm{SS}$, et al. Long-term outcome of bilateral lung volume reduction in 250 consecutive patients with emphysema. J Thorac Cardiovasc Surg 2003;125(3):513.

6. Ingenito EP, Wood DE, Utz JP. Bronchoscopic lung volume reduction in severe emphysema. Proc Am Thorac Soc 2008;5(4): 454-460.

7. Venuta F, de Giacomo T, Rendina EA, Ciccone AM, Diso D, Perrone A, et al. Bronchoscopic lung-volume reduction with oneway valves in patients with heterogenous emphysema. Ann Thorac Surg 2005;79(2):411-416.

8. Wood DE, McKenna R Jr, Yusen RD, Sterman DH, Ost DE, Springmeyer SC, et al. A multicenter trial of an intrabronchial valve for treatment of severe emphysema. J Thorac Cardiovasc Surg 2007; 133(1):65-73

9. Strange C, Herth FJF, Kovitz KL, McLennan G, Ernst A, Goldin J, et al. Design of the Endobronchial Valve for Emphysema Palliation Trial (VENT): a non-surgical method of lung volume reduction. BMC Pulm Med 2007;7(1):10.

10. Sabanathan S, Richardson J, Pieri-Davies S. Bronchoscopic lung volume reduction. J Cardiovasc Surg 2003;44(1):101-108.

11. Hopkinson NS, Toma TP, Hansell DM, Goldstraw P, Moxham J, Geddes DM, et al. Effect of bronchoscopic lung volume reduction on dynamic hyperinflation and exercise in emphysema. Am J Respir Crit Care Med 2005;171(5):453-460.

12. Yim A, Hwong T, Lee TW, Li W, Lam S, Yeung TK, et al. Early results of endoscopic lung volume reduction for emphysema. J Thorac Cardiovasc Surg 2004;127(6):1564-1573.

13. Wan IYP, Toma TP, Geddes DM, Snell G, Williams T, Venuta F, et al. Bronchoscopic lung volume reduction for endstage emphysema: report on the first 98 patients. Chest 2006;129(3): 518-526.

14. Calverley PMA, Anderson JA, Celli B, Ferguson GT, Jenkins C, Jones PW, et al. Salmeterol and fluticasone propionate and survival in chronic obstructive pulmonary disease. N Engl J Med 2007;356(8): 775-789.

15. Jenkins M, Vaughan P, Place D, Kornaszewska M. Endobronchial valve migration. Eur J Cardiothorac Surg 2011;40(5):1258-1260.

16. Kotecha S, Westall GP, Holsworth L, Pham A, Williams TJ, Snell GI. Long term outcomes from bronchoscopic lung volume reduction using a bronchial prosthesis. Respirology 2011;16(1): 167-173. 
17. Fishman A, Martinez F, Naunheim K, Piantadosi S, Wise R, Ries A, et al. A randomized trial comparing lung-volume-reduction surgery with medical therapy for severe emphysema. N Engl J Med 2003; 348(21):2059-2073.

18. Sciurba FC, Ernst A, Herth FJF, Strange C, Criner GJ, Marquette $\mathrm{CH}$, et al. A randomized study of endobronchial valves for advanced emphysema. N Engl J Med 2011;363(13):12331244.
19. de Oliveira HG, Macedo-Neto AV, John AB, Jungblut S, Prolla JC, Menna-Barreto SS, et al. Transbronchoscopic pulmonary emphysema treatment 1-month to 24-month endoscopic follow-up. Chest 2006;130(1):190-199.

20. Toma T, Hopkinson J, Hillier J, Ujita M, Dusmet M, Goldstraw P, et al. Effect of unilateral total lobar occlusion with bronchoscopic valve implants in patients with severe heterogeneous emphysema (abstract). Am J Respir Crit Care Med 2004;165:A576. 